\title{
Effects of Prostacyclin and Milrinone on Pulmonary Hemodynamics in Newborn Lambs With Persistent Pulmonary Hypertension Induced by Ductal Ligation
}

\author{
NASIR RASHID, FREDERICK C. MORIN III, DANIEL D. SWARTZ, RITA M. RYAN, KAREN A. WYNN, HUAMEI WANG, \\ SATYAN LAKSHMINRUSIMHA, AND VASANTH H. KUMAR
}

Department of Pediatrics, Center for Developmental Biology of the Lung, State University of New York at Buffalo, Buffalo, New York, 14214

\begin{abstract}
Prostacyclin $\left(\mathrm{PGI}_{2}\right)$ stimulates adenyl cyclase to synthesize cAMP within the vascular smooth muscle resulting in vasodilatation. Milrinone inhibits cAMP clearance by phosphodiesterase type III. We studied the dose response of pulmonary and systemic hemodynamics to intratracheal (IT) $\mathrm{PGI}_{2}$ in newborn lambs with pulmonary hypertension $(\mathrm{PH})$ and whether intravenous milrinone potentiate these effects. IT-PGI 2 at varying doses was administered to lambs with $\mathrm{PH}$ induced by prenatal ductal ligation. IT-PGI ${ }_{2}$ doses were repeated in the presence of intravenous milrinone (bolus- 100 $\mu \mathrm{g} / \mathrm{kg}$ followed by infusion at $1 \mu \mathrm{g} / \mathrm{kg} / \mathrm{min}$ ). Increasing doses of IT-PGI 2 significantly decreased mean pulmonary arterial pressures (PAP) and pulmonary vascular resistance (PVR) and increased pulmonary blood flow (PBF). Intravenous milrinone by itself produced a significant reduction in PVR and a significant increase in PBF. Intravenous milrinone significantly shortened the onset, prolonged the duration and degree of pulmonary vasodilation produced by $\mathrm{PGI}_{2}$. We conclude that intravenous milrinone potentiates the pulmonary vasodilator effects of $\mathrm{PGI}_{2}$ at lower doses. (Pediatr Res 60: 624-629, 2006)
\end{abstract}

$\mathrm{P}$ PHN is a disorder of term and near term infants with significant morbidity and mortality. PPHN results from disruption of the normal decrease in PVR at birth. $\mathrm{PGI}_{2}$, the main cyclo-oxygenase product of arachidonic acid in the vascular tissue, is a potent vasodilator and its actions are mediated by cAMP $(1,2)$. It is one of the important mediators of the decrease in PVR at birth $(3,4) . \mathrm{PGI}_{2}$ has been used widely in the treatment of adults with $\mathrm{PH}$. Although there are reports of $\mathrm{PGI}_{2}$ being used anecdotally in human infants $(5,6)$, systematic studies on the dose response effects of $\mathrm{PGI}_{2}$ in PPHN are lacking. Milrinone selectively inhibits PDE3, resulting in accumulation of cAMP in myocardium and vascular smooth muscle, improving myocardial performance and producing vasodilation. Milrinone has been used in patients to improve pulmonary hemodynamics in association with systemic hemodynamic dysfunction $(7,8)$. Studies on the use of milrinone in neonates are lacking. Figure 1 shows the $\mathrm{PGI}_{2}-$

Received January 12, 2006; accepted July 4, 2006

Correspondence: Vasanth H. Kumar, M.D., Division of Neonatology, The Women and Children's Hospital of Buffalo, 219, Bryant Street, Buffalo, NY 14222; e- mail: vkumar3@buffalo.edu

VHK was supported by the Buswell Grant from the School of Medicine and Biomedical Sciences, State University of New York at Buffalo.
cAMP signal transduction pathway in the vascular smooth muscle. $\mathrm{PGI}_{2}$ and milrinone in combination can act synergistically in increasing cAMP levels and hence enhance the relaxation of the vascular smooth muscle.

The newborn pulmonary circulation is different from the adult pulmonary circulation in its anatomy and physiology $(9,10)$. The response of the infant with PPHN to NO is closer to that of newborn lambs with persistent pulmonary hypertension induced by ligation of the ductus arteriosus (11) than it is to the response of adult humans with $\mathrm{PH}$. Examination of the responses to manipulating cAMP with $\mathrm{PGI}_{2}$ and milrinone in such lambs seemed warranted in advance of clinical trials. Thus we studied the dose response to IT $\mathrm{PGI}_{2}$, the response to intravenous milrinone and enhancement of the effect of $\mathrm{PGI}_{2}$ by milrinone in newborn lambs with $\mathrm{PH}$ induced by ligation of the ductus arteriosus.

\section{METHODS}

The study was performed at the Center for Developmental Lung Biology at the State University of New York (SUNY) at Buffalo. In a well-established lamb model of PPHN, ligation of the ductus arteriosus $9 \mathrm{~d}$ before delivery causes PPHN (12-14). These studies were approved by the Institutional Animal Care and Use Committee (IACUC) at SUNY, Buffalo.

Fetal ductal ligation was performed via thoracotomy at $129 \mathrm{~d}$ of gestation $($ term $=146 \mathrm{~d})$ as previously described (13). Time dated pregnant ewes $(n=$ 6 ) were brought to the laboratory animal facility $24-72 \mathrm{~h}$ before surgery. The ewe was intubated after intravenous pentothal $(750 \mathrm{mg})$ and ventilated with $0.5-1 \%$ isoflurane in oxygen. A left lateral thoracotomy was performed in the fourth intercostal space of the fetus, and the ductus arteriosus ligated. The fetal was then returned to the uterus and the abdominal wall was closed. The ewe was allowed to recover for $9 \mathrm{~d}$. At $138 \mathrm{~d}$ gestation, the ewe was anesthetized and the fetus was partially exteriorized via hysterotomy, the carotid artery and jugular vein were exposed, and polyvinyl catheters were inserted and advanced into the aorta and right atrium, respectively. A left thoracotomy was performed and polyvinyl catheters placed in the main pulmonary artery (PA) and left atrium (LA). An ultrasonic flow transducer (Transonics Systems Inc., Ithaca, NY) was placed around the main PA. The lamb was then intubated by direct visualization and the endotracheal tube secured. The lambs were delivered and placed under an infant warmer to maintain temperature at $39^{\circ} \mathrm{C}$. Lambs were covered in a plastic bag to prevent heat loss. Ventilation was initiated with a time cycled pressure controlled

Abbreviations: IT, intratracheal; PAP, pulmonary arterial pressure; PDE 3, phosphodiesterase type 3; $\mathbf{P G I}_{\mathbf{2}}$, prostacyclin; $\mathbf{P H}$, pulmonary hypertension; PPHN, persistent pulmonary hypertension of the newborn; PVR, pulmonary vascular resistance

DOI: 10.1203/01.pdr.0000242343.84510.81 


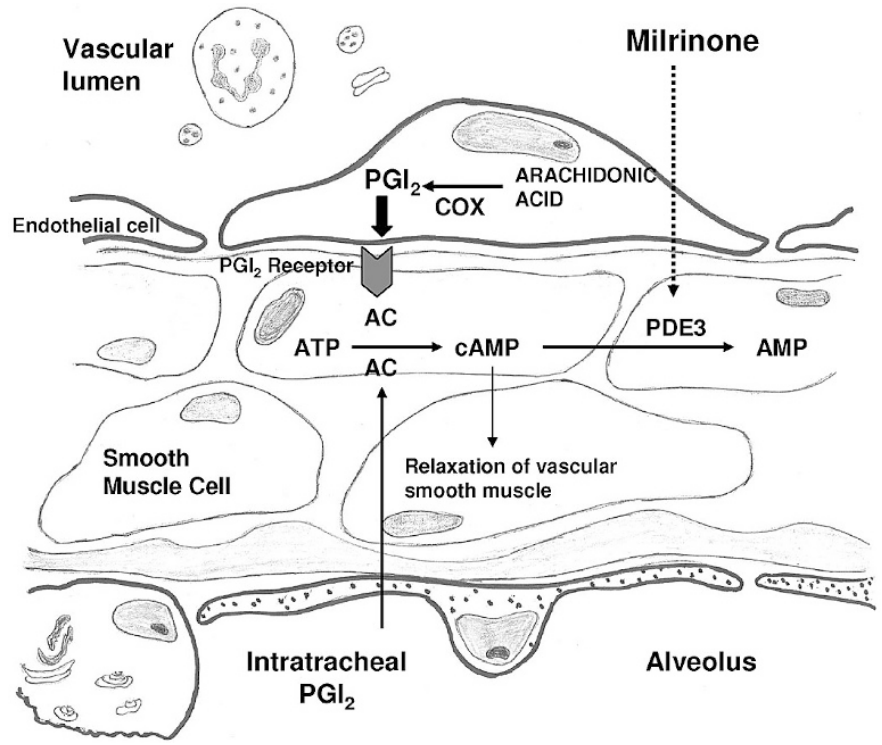

Figure 1. Signal transduction pathway of $\mathrm{PGI}_{2}-\mathrm{cAMP}$ system. $\mathrm{PGI}_{2}$ and milrinone increase cAMP by different mechanisms and hence combination of these two therapies will greatly increase cAMP levels enhancing the relaxation of the vascular smooth muscle. $C O X$, cyclo-oxygenase; $A C$, adenylate cyclase.

Sechrist ventilator (Sechrist Industries Inc., Anaheim, CA) at a rate of 60, positive inspiratory pressure (PIP) of $24-26 \mathrm{~cm}$ of $\mathrm{H}_{2} 0$, positive endexpiratory pressure (PEEP) of $4-5 \mathrm{~cm}$ of $\mathrm{H}_{2} \mathrm{O}$, Inspiratory time (I-time) of $33 \%$, and fraction of inspired oxygen $\left(\mathrm{FiO}_{2}\right)$ of 1.0. Initial stabilization included IV fluids at $100 \mathrm{~mL} / \mathrm{kg} / \mathrm{d}$, monitoring blood pressure, heart rate, temperature, oxygen saturation, arterial blood gases (ABG), glucose, and electrolytes. The lambs were sedated with fentanyl infusion $(3 \mu \mathrm{g} / \mathrm{kg} / \mathrm{h})$ and also received fentanyl bolus of $5 \mu \mathrm{g} / \mathrm{kg}$ i.v. when needed. The lambs were paralyzed with pancuronium $(0.1 \mathrm{mg} / \mathrm{kg} \mathrm{q} \mathrm{3-4} \mathrm{prn]} \mathrm{at} \mathrm{birth} \mathrm{and} \mathrm{prn.} \mathrm{Lambs}$ received normal saline or whole cord blood for low mean systemic blood pressure (SBP) of $<35 \mathrm{~mm} \mathrm{Hg}$ and bicarbonate for base deficit of $\geq 8 \mathrm{mEq} / \mathrm{L}$. Whenever the lambs received supportive therapy such as blood products, bicarbonate and volume, we deferred initiation of $\mathrm{PGI}_{2}$ protocols for at least $30 \mathrm{~min}$, to minimize the effects of these therapies on hemodynamic variables. ABG were done frequently during stabilization to maintain $\mathrm{PaCO}_{2}$ between 35 and $55 \mathrm{~mm} \mathrm{Hg}$ and $\mathrm{pH}$ between 7.35 and 7.45. $\mathrm{FiO}_{2}$ was kept at 1.0 during the study. All catheters were connected to a physiologic recorder (Gould Instrument Systems, Inc., Valley View, OH) for monitoring of SBP, PAP and left atrial pressure (LAP). The flow probe was connected to the flow meter
(Transonic Systems Inc., Ithaca, NY) for monitoring of pulmonary blood flow (PBF). PVR was calculated using the standard formula: PVR $=(\mathrm{PAP}-$ LAP)/PBF.

Delivery of prostacyclin and milrinone. $\mathrm{PGI}_{2}$ (Sigma Chemical Co., St. Louis, MO) was prepared fresh immediately before the start of the experiment using glycine buffer. $\mathrm{PGI}_{2}$ was delivered as a bolus dose directly into the trachea. The doses of $\mathrm{PGI}_{2}$ studied were 200, 500, 1000, 2000, 4000, and 8000 $\mathrm{ng} / \mathrm{kg}$ given in random order. Glycine buffer (vehicle) was used as a control. All IT doses were prepared to a final volume of $2.5 \mathrm{~mL}$. The doses were delivered by the feeding tube, cut to exact length, so that the doses are delivered $0.5-1 \mathrm{~cm}$ beyond the tip of the endotracheal (ET) tube. Autopsy studies show that the ET tube tip is generally $4 \mathrm{~cm}$ above the carina. Hemodynamic changes were recorded before and after administration of each dose. A 30-min interval was maintained between doses to allow for the PAP to come back to the baseline (pre-dose values). On completion of all of the doses of $\mathrm{PGI}_{2}$, milrinone (Baxter Healthcare Corporation, Deerfield, IL) was administered as a bolus dose of $100 \mu \mathrm{g} / \mathrm{kg}$ i.v. over $5 \mathrm{~min}$ followed by an infusion at $1 \mu \mathrm{g} / \mathrm{kg} / \mathrm{min}$. Baseline hemodynamic measurements were recorded before and for an hour after administration of milrinone. $\mathrm{PGI}_{2}$ was then repeated randomly by IT route at the same doses while on intravenous milrinone infusion. Hemodynamic measurements and $\mathrm{ABG}$ were done before and after the IT bolus dose. These measurements were made continuously to determine the onset and duration of action of $\mathrm{PGI}_{2}$. Onset of action was defined as the time for any decrease in PAP after administration of $\mathrm{PGI}_{2}$. Duration of action was defined as the time elapsed since administration of $\mathrm{PGI}_{2}$ for the PAP to decrease and then come back to its original baseline. Experiments were done in six newborn lambs with PPHN. Data are expressed as mean \pm SEM, with $n$ representing the number of animals. Statistical comparisons of the curves were performed with one way or repeated measures ANOVA as appropriate. Fisher's post hoc test was used as needed to compare among groups. All statistical analysis was performed with StatView software (Abacus Concepts, Berkley, CA). Significance was accepted at $p<0.05$.

\section{RESULTS}

Tables 1 and 2 summarize the data of PVR, PAP, PBF, and SBP after randomly administered IT $\mathrm{PGI}_{2}$ and intravenous milrinone when given separately (Table 1 ) and in combination (Table 2). The baseline PAP before administration of $\mathrm{PGI}_{2}$ doses was between 60 and $65 \mathrm{~mm} \mathrm{Hg}$ (Table 1). Percent changes in pulmonary hemodynamics are presented in Figure 2. $\mathrm{PGI}_{2}$ significantly decreased PAP at all doses but the vehicle did not (Fig. 2A). There was a significant increase in PBF with increasing doses of IT $\mathrm{PGI}_{2}$ (Fig. $2 B$ ). IT $\mathrm{PGI}_{2}$ decreases PVR from predose baseline values in a dose dependent manner (Fig. 2C). Vehicle did not affect hemodynamics and $\mathrm{PGI}_{2}$ did not affect SBP.

Table 1. Hemodynamic variables following randomly administered IT PGI $I_{2}$ or intravenous milrinone in newborn lambs with pulmonary hypertension induced by antenatal ductal ligation

\begin{tabular}{|c|c|c|c|c|c|c|c|c|c|}
\hline \multirow[b]{2}{*}{ Drug } & \multirow[b]{2}{*}{ Dose } & \multicolumn{8}{|c|}{ Hemodynamic variable } \\
\hline & & Pre & Post & Pre & Post & Pre & Post & Pre & Post \\
\hline Vehicle & $2.5 \mathrm{~mL}$ & $63.6(3)$ & $64.6(4)$ & $89(4)$ & $98(9)$ & $0.552(0.1)$ & $0.52(0.01)$ & $57(5)$ & $57(7)$ \\
\hline \multirow{5}{*}{$\begin{array}{l}\text { IT PGI } \\
\quad(\mathrm{ng} / \mathrm{kg} \text { in } 2.5 \mathrm{~mL} \text { of buffer) }\end{array}$} & 200 & $60.5(5)$ & $57.8(5)$ & $95(11)$ & $103(11)$ & $0.545(0.1)$ & $0.482(0.09)$ & $56(1)$ & $56(2)$ \\
\hline & 1000 & $64.6(3)$ & $55.6(1)^{*}$ & $83(8)$ & $104(3)^{*}$ & $0.669(0.07)$ & $0.485(0.06)^{*}$ & $57(4)$ & $56(3)$ \\
\hline & 2000 & $62.6(3)$ & $53.8(1)^{*}$ & $96(8)$ & $116(15)$ & $0.519(0.01)$ & $0.363(0.02)^{*}$ & $51(3)$ & $48(4)$ \\
\hline & 4000 & $64.3(5)$ & $55.6(6)$ & $92(8)$ & $122(15)$ & $0.62(0.08)$ & $0.393(0.07)^{*}$ & $56(5)$ & $53(5)$ \\
\hline & 8000 & $63(3)$ & $55.5(4)$ & $97(16)$ & $133(14)$ & $0.617(0.07)$ & $0.376(0.01)^{*}$ & $54(3)$ & $49(4)$ \\
\hline $\begin{array}{l}\text { Intravenous milrinone } \\
\qquad(\mu \mathrm{g} / \mathrm{kg} / \mathrm{min})\end{array}$ & $\begin{array}{l}\text { Bolus }=100 \mu \mathrm{g} / \mathrm{kg} \text { and } \\
\text { infusion of } 1 \mu \mathrm{g} / \mathrm{kg} / \mathrm{min}\end{array}$ & $57.8(2)$ & $54(5)$ & $110(15)$ & $130(16)$ & $0.503(0.06)$ & $0.383(0.03)^{*}$ & $54(3)$ & $51(4)$ \\
\hline
\end{tabular}

Data represents mean (SEM) from 6 newborn lambs. SBP, systemic blood pressure

$* p<0.05$ compared with pre-dose value by Fisher's post hoc test. 
Table 2. Hemodynamic variables following combination of IT $\mathrm{PGI}_{2}$ and intravenous milrinone in newborn lambs with pulmonary hypertension induced by antenatal ductal ligation

\begin{tabular}{|c|c|c|c|c|c|c|c|c|c|}
\hline \multirow[b]{3}{*}{ Drug } & \multirow[b]{3}{*}{ Dose } & \multicolumn{8}{|c|}{ Hemodynamic variable } \\
\hline & & \multicolumn{2}{|c|}{ Mean PAP (mm Hg) } & \multicolumn{2}{|c|}{$\mathrm{PBF}(\mathrm{mL} / \mathrm{kg} / \mathrm{min})$} & \multicolumn{2}{|c|}{ PVR(mm Hg/mL/kg/min) } & \multicolumn{2}{|c|}{ Mean SBP (mm Hg) } \\
\hline & & Pre & Post & Pre & Post & Pre & Post & Pre & Post \\
\hline Vehicle(glycine buffer) & $2.5 \mathrm{~mL}$ & $53.3(3)$ & $49.6(2)$ & $136(19)$ & $129(24)$ & $0.373(0.08)$ & $0.382(0.09)$ & $40(1)$ & $41(1)$ \\
\hline \multirow{6}{*}{$\begin{array}{l}\text { IT } \mathrm{PGI}_{2} \\
\quad(\mathrm{ng} / \mathrm{kg} \text { in } 2.5 \mathrm{~mL} \text { of buffer) }\end{array}$} & 200 & $52.2(4)$ & $48.4(2)$ & $98(12)$ & $105(10)$ & $0.5(0.01)$ & $0.423(0.03)$ & $43(2)$ & $43(1)$ \\
\hline & 500 & $52.8(3)$ & $46.4(2)$ & $116(15)$ & $124(16)$ & $0.453(0.04)$ & $0.329(0.03)^{*}$ & $46(3)$ & $46(3)$ \\
\hline & 1000 & $51.8(3)$ & $39.8(2)^{*}$ & $98(14)$ & $111(13)$ & $0.543(0.13)$ & $0.334(0.06)^{*}$ & $43(6)$ & $44(4)$ \\
\hline & 2000 & $52.4(2)$ & $41.6(1)^{*}$ & $119(12)$ & $131(9)$ & $0.413(0.05)$ & $0.282(0.03)^{*}$ & $48(3)$ & $44(4)$ \\
\hline & 4000 & $54.2(3)$ & $42.4(2)^{*}$ & $116(12)$ & $132(17)$ & $0.437(0.06)$ & $0.292(0.03)^{*}$ & $46(3)$ & $44(5)$ \\
\hline & 8000 & $43.6(1)$ & $37.3(2)$ & $75(20)$ & $93(15)$ & $0.591(0.18)$ & $0.344(0.03)$ & $41(3)$ & $35(3)$ \\
\hline
\end{tabular}

Data represents mean (SEM) from six newborn lambs. SBP, systemic blood pressure.

$* p<0.05$ compared with pre-dose value by Fisher's post hoc test.
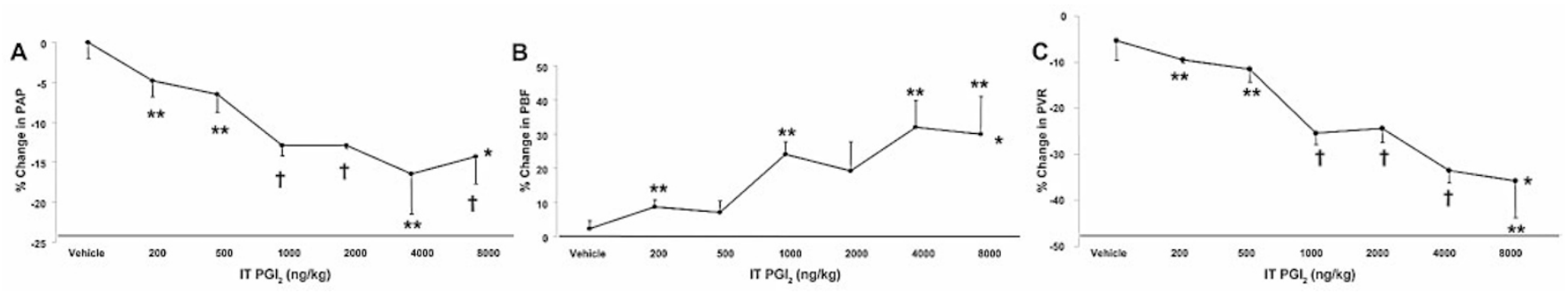

Figure 2. Dose response effects of randomly administered $\mathrm{IT} \mathrm{PGI}_{2}$ on percentage change in mean PAP $(A), \operatorname{PBF}(B)$, and PVR $(C)$ in newborn lambs with fetal ductal ligation induced pulmonary hypertension. Data represent mean \pm SEM of six newborn lambs. $* p<0.05$, ANOVA repeated measures; $* * p<0.01 ; \dagger p$ $<0.001$ compared with predose values, Fisher's Post hoc test.

Intravenous milrinone by itself decreased PVR by $22 \%$ (Fig. 3). Intravenous milrinone increased pulmonary blood flow by $18 \%$ (Fig. 3). The effect of intravenous milrinone on mean PAP and mean SBP were not significant. IT $\mathrm{PGI}_{2}$ decreased mean PAP and PVR in the presence of intravenous milrinone in a dose-dependent manner (Fig. 4, $A$ and $C$ ). Intravenous milrinone enhanced the response to $\mathrm{PGI}_{2}$. At doses of 500 and $1000 \mathrm{ng} / \mathrm{kg} \mathrm{PGI}_{2}$ reduced mean PAP to a greater extent in the presence of intravenous milrinone than it did alone (Fig. 5A). Similarly, $\mathrm{PGI}_{2}$ produced a greater de-

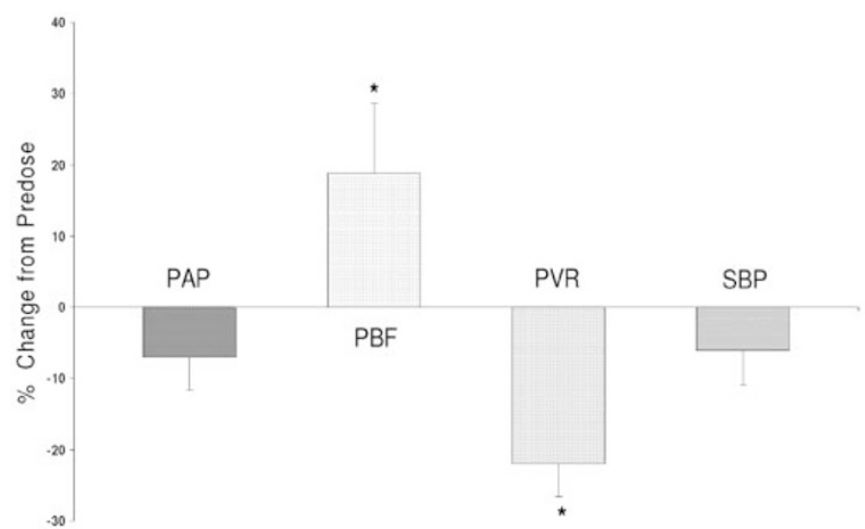

Figure 3. Percentage change in PVR, mean PAP, mean systemic blood pressure, and pulmonary blood flow after intravenous milrinone $(100 \mu \mathrm{g} / \mathrm{kg}$ bolus followed by infusion of $1 \mu \mathrm{g} / \mathrm{kg} / \mathrm{min}$ for $60 \mathrm{~min}$ ) in newborn lambs with fetal ductal ligation induced pulmonary hypertension. Data represent mean \pm SEM in six lambs. $* p<0.05$ compared with predose values, Fisher's post hoc test. crease in PVR in the presence of intravenous milrinone at doses of $200 \mathrm{ng} / \mathrm{kg}$ and $500 \mathrm{ng} / \mathrm{kg}$ than it did alone (Fig. 5B). Milrinone facilitates the response to $\mathrm{PGI}_{2}$ at lower doses.

The onset of action of IT PGI ${ }_{2}$ on PAP was seen within $60 \mathrm{~s}$ of administration of the drug. The range of onset of action varied from 39-60 s (49.7 $\pm 10.1 \mathrm{~s})$ for $\mathrm{PGI}_{2}$ alone compared with $10-20 \mathrm{~s}(15.4 \pm 4.1 \mathrm{~s})$ for $\mathrm{PGI}_{2}$ in the presence of intravenous milrinone (Fig. 6A). The onset of action of $\mathrm{PGI}_{2}$ was significantly shorter in the presence of milrinone. The duration of action of $\mathrm{PGI}_{2}$ was significantly prolonged in the presence of intravenous milrinone compared with $\mathrm{PGI}_{2}$ alone (Fig. 6B). The range of duration of action was 5-7 $\mathrm{min}(6.13$ $\pm 1.01 \mathrm{~min})$ for $\mathrm{PGI}_{2}$ alone compared with $8-11 \mathrm{~min}(9.36 \pm$ $1.18 \mathrm{~min}$ ) for $\mathrm{PGI}_{2}$ in the presence of intravenous milrinone.

No significant difference in mean SBP was noted before and after IT $\mathrm{PGI}_{2}$ at all doses studied. Similarly, there was no difference in mean SBP before and after IT $\mathrm{PGI}_{2}$ in the presence of milrinone. Lower doses of $\mathrm{PGI}_{2}$ produced only minimal change (0\% to $2 \%$ ) in mean SBP compared with a $6-12 \%$ decrease at higher doses (doses $>2000 \mathrm{ng} / \mathrm{kg}$ ) both in the absence and presence of intravenous milrinone. The data on mean PAP to mean SBP ratio is shown in Figure 7. PAP to SBP ratio was significantly lower following IT $\mathrm{PGI}_{2}$ compared with predose (Fig. 7A). Similarly, IT $\mathrm{PGI}_{2}$ in the presence of milrinone had a significantly lower PAP/SBP ratio compared with predose (Fig. $7 B$ ). This effect was more pronounced at lower doses $\left(<2000 \mathrm{ng} / \mathrm{kg}\right.$ of $\left.\mathrm{PGI}_{2}\right)$. IT $\mathrm{PGI}_{2}$ alone or with intravenous milrinone did not produce any significant difference in arterial blood gas parameters including $\mathrm{PaO}_{2}, \mathrm{pH}$, and $\mathrm{Pa}_{\mathrm{co} 2}$ before and after various doses of $\mathrm{PGI}_{2}$. 

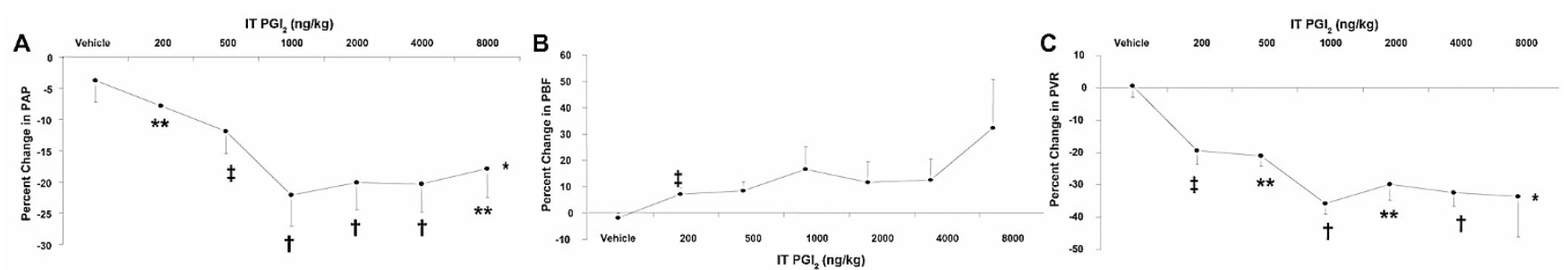

Figure 4. Percent change in PAP $(A)$, pulmonary blood flow $(B)$, and PVR $(C)$ of randomly administered $\mathrm{IT} \mathrm{PGI}_{2}$ in the presence of intravenous milrinone (bolus $=100 \mu \mathrm{g} / \mathrm{kg}$; infusion $=1 \mu \mathrm{g} / \mathrm{kg} / \mathrm{min}$ ) in newborn lambs with fetal ductal ligation induced pulmonary hypertension. Data represent mean $\pm \mathrm{SEM}$ of six newborn lambs. ${ }^{*} p<0.05$, ANOVA repeated measures; $\ddagger p<0.05, * * p<0.01 ; \dagger p<0.001$ compared with predose values, Fisher's post hoc test.
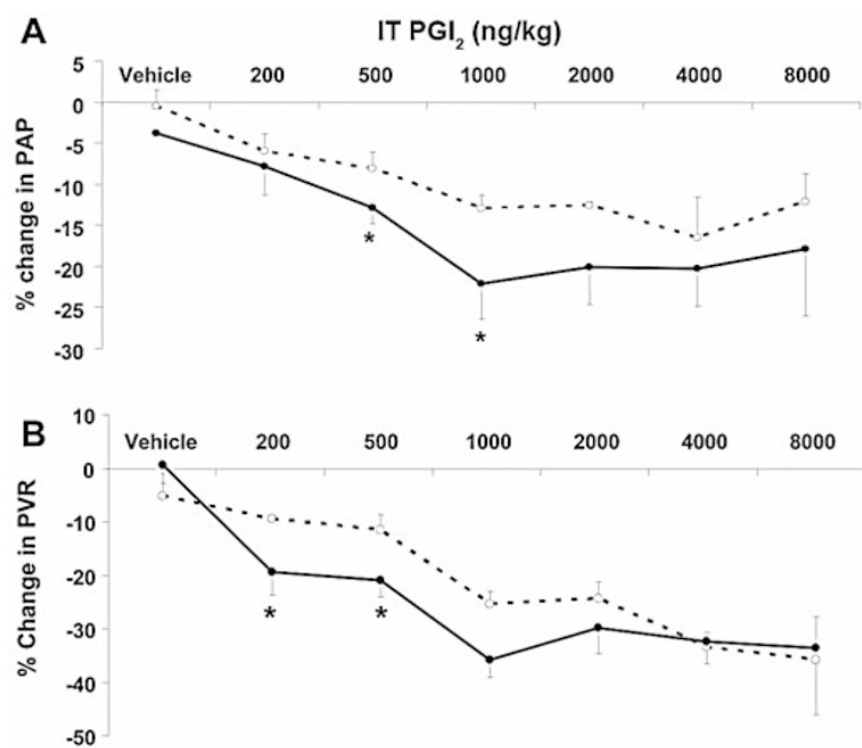

Figure 5. Comparison of percent change in $\mathrm{PAP}(A)$ and $\mathrm{PVR}(B)$ of $\mathrm{IT}_{\mathrm{PGI}}$ alone (dashed line) with IT $\mathrm{PGI}_{2}$ plus intravenous milrinone (solid line) in newborn lambs with fetal ductal ligation-induced PH. Data represent mean \pm SEM of six newborn lambs. IT $\mathrm{PGI}_{2}$ doses of 500 and $1000 \mathrm{ng} / \mathrm{kg}$ significantly reduced PAP in the presence of intravenous milrinone compared with IT $\mathrm{PGI}_{2}$ alone. Similarly IT $\mathrm{PGI}_{2}$ doses of 200 and $500 \mathrm{ng} / \mathrm{kg}$ reduced PVR in the presence of milrinone. ${ }^{*} p<0.05$ compared with similar dose of IT $\mathrm{PGI}_{2}$; Fisher's post hoc test.

\section{DISCUSSION}

Closure of ductus arteriosus of the fetal lamb 7-10 d before delivery causes persistent PH after birth (13). In our experiments, mean PAP soon after birth before start of the study were between 60-65 mm Hg. Ductal ligation also induces an increase in the proportion of partially and fully muscularized pulmonary arteries at the level of the terminal bronchiole and within the acinus (14). Thus, the anatomic and physiologic changes in the ductal ligation model of PPHN are similar to alterations reported in human neonates dying with idiopathic PPHN (14). This model of PH of the newborn has been used extensively in the preclinical studies of inhaled nitric oxide (iNO) on pulmonary hemodynamics and survival $(12,15,16)$.

The effects of aerosolized $\mathrm{PGI}_{2}$ in $\mathrm{PH}$ in adults are well studied. Aerosolized $\mathrm{PGI}_{2}$ has been shown to be at least as effective as inhaled nitric oxide in decreasing $\mathrm{PH}$ in both animals and humans $(17,18)$. Aerosolized $\mathrm{PGI}_{2}$ selectively dilates the pulmonary circulation and redistributes PBF away from nonventilated lung regions (19) and has been shown to improve oxygenation in patients with ARDS or acute lung injury (19-21). Aerosolized $\mathrm{PGI}_{2}$ reduced pulmonary pressures and improved right ventricular stroke volume in patients with PH undergoing cardiac surgery (22). The data on the effects in the neonate are anecdotal $(5,23,24)$. IT instillation of $\mathrm{PGI}_{2}$ at $50 \mathrm{ng} / \mathrm{kg}$ when injected as a bolus dose in four preterm infants with documented PH resulted in a significantly improved oxygenation index without systemic hypotension (23). Neither human nor animal studies have addressed the role of $\mathrm{PGI}_{2}$ as a first line therapy in the management of PPHN soon after birth nor has there been determination of the pulmonary hemodynamic response to various doses of $\mathrm{PGI}_{2}$ in neonates.

Most of the studies in adults with $\mathrm{PH}$ have delivered $\mathrm{PGI}_{2}$ by intravenous or aerosolized route. As noted above, $\mathrm{PGI}_{2}$ was given by IT instillation in a pilot study of neonates with apparent success. Each of these methods of drug delivery to the lung has drawbacks in distribution, deposition with aerosols or systemic delivery with intravenous administration. As

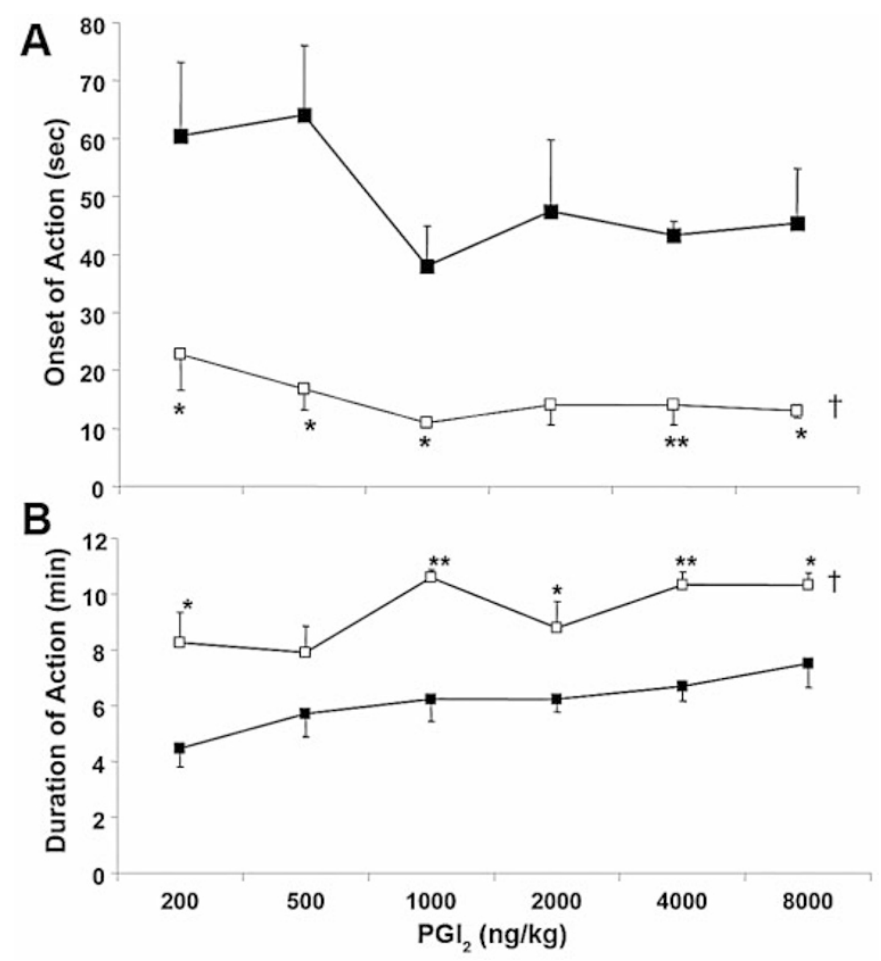

Figure 6. Onset $(A)$ and duration $(B)$ of action of $\mathrm{PGI}_{2}$ alone (open squares) and in the presence of intravenous milrinone (shaded triangles). The onset of action was significantly shorter and the duration of action was significantly longer in the presence of milrinone. $\dagger p<0.05$ by ANOVA repeated measures vs $\mathrm{PGI}_{2}$ alone. $* p<0.05$ and $* * p<0.01$ by Fisher's post hoc test $v s$ corresponding $\mathrm{PGI}_{2}$ doses. 

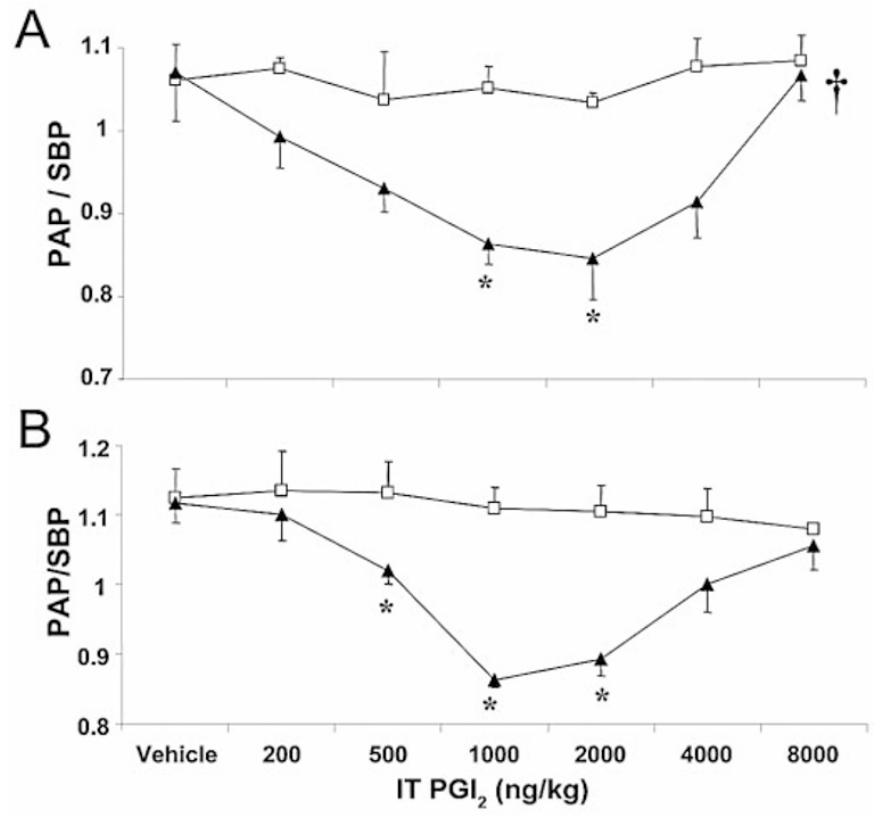

Figure 7. Changes in $\mathrm{PAP} / \mathrm{SBP}$ ratio following IT $\mathrm{PGI}_{2}$ with and without intravenous milrinone. (A) Represents PAP/SBP ratio before and after IT $\mathrm{PGI}_{2}$. $(B)$ Represents PAP/SBP ratio before and after IT PGI ${ }_{2}$ in the presence of intravenous milrinone. Mean values are given and error bars represent SE. $\square$ (open squares) represents the ratio before $\mathrm{PGI}_{2}$ and $\boldsymbol{\Delta}$ represents data post IT bolus of $\mathrm{PGI}_{2} .{ }^{*} p<0.05$ by Fisher's post hoc test; $\uparrow p<0.05$ by ANOVA repeated measures.

we were doing the first dose response studies in this very labor-intensive model of fetal ductal ligation induced PPHN, we chose the IT route to be certain of the dose deposited in the lung. Despite potential limitation on distribution, PAP responses were seen within a minute in all of our studies and lasted 5-11 min ( $\mathrm{PGI}_{2}$ half life of 90-120 s) of administration of the drug, indicating the effectiveness of the IT route of administration in these experiments. The doses of $\mathrm{PGI}_{2}$ used were extrapolated from clinical and animal studies of inhaled $\mathrm{PGI}_{2}$. In our study, all doses of IT $\mathrm{PGI}_{2}$ effectively and selectively reduced PAP and PVR with minimal effect on SBP. As PAP and resistance decreased and pulmonary blood flow increased, it is probable that systemic blood flow and

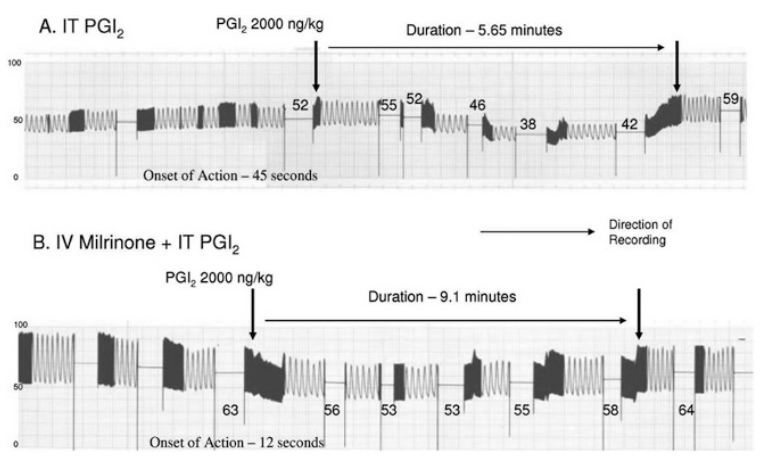

Figure 8. Graphic depiction of a representative study demonstrating the effects of $\mathrm{PGI}_{2}$ on PAP. The kinetic information about the duration of response to $\mathrm{PGI}_{2}$ alone $(A)$ is compared with same dose of $\mathrm{PGI}_{2}$ in the presence of intravenous milrinone $(B)$. Intravenous milrinone shortens the onset and prolongs the duration of action of $\mathrm{PGI}_{2}$. The numbers adjacent to the recording indicate mean PAP in $\mathrm{mm} \mathrm{Hg}$. oxygen delivery increased. We failed to demonstrate any improvement in oxygenation with $\mathrm{PGI}_{2}$ either alone or with milrinone. This could be related not only to the significant intracardiac shunting of blood from right to left via the foramen ovale secondary to significant PH but also to intrapulmonary shunting in an instrumented, sick postoperative newborn lamb. Also, IT administration of the drug preferentially deposits the drug to a poorly ventilated, dependent part of the lung, limiting its effects on oxygenation.

In adult patients following cardiac surgery milrinone increased cardiac index and reduced pulmonary artery occlusion pressure and systemic vascular resistance (25). It decreased pulmonary arterial and venous vascular tone without increasing cardiac work or impairing pulmonary oxygenation in hypoxic dogs (26). A single $50 \mu \mathrm{g} / \mathrm{kg}$ i.v. bolus of milrinone produced a $31 \%$ reduction in PVR, a $42 \%$ increase in cardiac output, and a $12 \%$ reduction in mean PAP in adult patients with severe left ventricular dysfunction (27). Inhaled milrinone did not affect systemic arterial pressure in cardiac surgical patients with pulmonary hypertension (28). Milrinone as a loading dose of $50 \mu \mathrm{g} / \mathrm{kg}$ followed by an infusion of 0.5 $\mu \mathrm{g} / \mathrm{kg} / \mathrm{min}$ decreased PVR and SVR and increased cardiac index in neonates with low cardiac output following cardiac surgery (29). Dipyridamole, a PDE5 inhibitor had significant hemodynamic effects in both the pulmonary and systemic circulations of newborn lambs with PH (12). In our experiments, intravenous milrinone by itself decreased PVR and increased PBF with no significant affect on SBP. Our data demonstrate a good response in a lamb model of PPHN.

The use of PDE inhibitors for maintenance of the $\mathrm{PGI}_{2}$ induced second messenger cAMP may offer the possibility of prolonging and increasing the vasodilatory effect of nebulized $\mathrm{PGI}_{2}$ in the lung vasculature. A graphic depiction of decrease in PAP following IT PGI $2(2000 \mathrm{ng} / \mathrm{kg})$ from a representative study both in the presence and absence of intravenous milrinone is shown in Figure 8. In our studies, the onset of action was significantly shorter and the duration of action was significantly longer with $\mathrm{PGI}_{2}$ in the presence of intravenous milrinone compared with $\mathrm{PGI}_{2}$ alone. Co-administering $\mathrm{PGI}_{2}$ with a systemic PDE3 inhibitor not only produced a greater decrease in PVR at lower doses, but also prolonged the action of $\mathrm{PGI}_{2}$ on PAP. The shorter time to onset of action (measured in seconds) may not be clinically relevant but its longer duration of action (measured in minutes) may be of clinical interest. The short half-life of $\mathrm{PGI}_{2}$ makes it imperative to administer it as a continuous inhalation for sustained clinical benefit. Our study validates the use of this combination therapy in a newborn lamb model of PH. Administration of $\mathrm{PGI}_{2}$ by IT bolus is clinically impractical, but its administration by continuous nebulization along with intravenous milrinone seems relevant and practical in certain clinical situations.

Several studies have addressed the role of systemic PDE inhibitors in combination with inhaled $\mathrm{PGI}_{2}$ in adults (30-33). Doses in our experiments are similar to the doses used in the clinical management of patients with cardiac failure and cardiogenic or septic shock. Subthreshold systemic doses of monoselective PDE3 (motapizone), PDE4 (rolipram) and PDE5 (zaprinast), and dual-selective PDE 3/4 inhibitors cause 
significant amplification of the pulmonary vasodilatory response to inhaled $\mathrm{PGI}_{2}$, while limiting the hypotensive effect to the systemic circulation (31). Co-administration of PDE inhibitors with inhaled iloprost, a prostacyclin analogue, markedly enhanced the prostanoid-induced pulmonary artery pressure decrease while maintaining the lung selectivity of the vasodilatory response (32). The absence of data on cardiac output makes it difficult to comment on vascular selectivity in our experiments. The lack of cardiac output and systemic vascular resistance (SVR) measurements is a significant limitation to the study, which is a result of a conscious decision to not perform double thoracotomies (to measure cardiac output) in these sick newborn lambs. In the absence of SVR data we used PAP/SBP ratio as a marker of vascular selectivity. Even though a declining PAP/SBP ratio is helpful, it does not prove that SVR did not drop significantly. PAP to SBP ratio decreased with $\mathrm{PGI}_{2}$ both in the presence and absence of intravenous milrinone. The ratio was lower at lower doses when $\mathrm{PGI}_{2}$ was administered alone or with milrinone. However, the ratio increases at higher doses of $\mathrm{PGI}_{2}$ with a concomitant decrease in SBP and this effect could be exaggerated by intravenous milrinone. This observation has clinical implications. The clinician should avoid higher doses of $\mathrm{PGI}_{2}$ especially when it is co-administered with intravenous PDE3 inhibitor.

There is paucity of data on $\mathrm{PGI}_{2}$ with PDE3 inhibitors in newborn human or animals. We have demonstrated that IT $\mathrm{PGI}_{2}$ and intravenous milrinone each decrease PVR in a well-established newborn lamb model of PPHN. Systemic administration of milrinone in combination with $\mathrm{IT}^{\mathrm{PGI}_{2}}$ produced a synergistic response in reduction in PVR, more so at clinically relevant doses of 200 and $500 \mathrm{ng} / \mathrm{kg}$ (extrapolates to $20-50 \mathrm{ng} / \mathrm{kg} / \mathrm{min}$ over $10 \mathrm{~min}$ by aerosol). Combination of systemically administered milrinone with lower doses of $\mathrm{PGI}_{2}$ may enhance the pulmonary hemodynamic response with probably minor and clinically not relevant side effects on the systemic vasculature. These findings may be of relevance in the clinical management of infants with pulmonary hypertension.

\section{REFERENCES}

1. Moncada S, Gryglewski R, Bunting S, Vane JR 1976 An enzyme isolated from arteries transforms prostaglandin endoperoxides to an unstable substance that inhibits platelet aggregation. Nature 263:663-665

2. Vane JR, Botting RM 1995 Pharmacodynamic profile of prostacyclin. Am J Cardiol. 75:3A-10A

3. Leffler CW, Mitchell JA, Green RS 1984 Cardiovascular effects of leukotrienes in neonatal piglets. Role in hypoxic pulmonary vasoconstriction? Circ Res 55:780-787

4. Leffler CW, Tyler TL, Cassin S 1978 Effect of indomethacin on pulmonary vascular response to ventilation of fetal goats. Am J Physiol 234:H346-H351

5. Eronen M, Pohjavuori M, Andersson S, Pesonen E, Raivio KO 1997 Prostacyclin treatment for persistent pulmonary hypertension of the newborn. Pediatr Cardiol $18: 3-7$

6. Soditt V, Aring C, Groneck P 1997 Improvement of oxygenation induced by aerosolized prostacyclin in a preterm infant with persistent pulmonary hypertension of the newborn. Intensive Care Med 23:1275-1278

7. Jaski BE, Fifer MA, Wright RF, Braunwald E, Colucci WS 1985 Positive inotropic and vasodilator actions of milrinone in patients with severe congestive heart failure.
Dose-response relationships and comparison to nitroprusside. J Clin Invest 75:643649

8. Siostrzonek P, Koreny M, Delle-Karth G, Haumer M, Koller-Strametz J, Heinz G 2000 Milrinone therapy in catecholamine-dependent critically ill patients with heart failure. Acta Anaesthesiol Scand 44:403-409

9. Morin FC 3rd, Egan EA 1992 Pulmonary hemodynamics in fetal lambs during development at normal and increased oxygen tension. J Appl Physiol 73:213-218

10. Teitel DF, Iwamoto HS, Rudolph AM 1990 Changes in the pulmonary circulation during birth-related events. Pediatr Res 27:372-378

11. Ziegler JW, Ivy DD, Kinsella JP, Abman SH 1995 The role of nitric oxide, endothelin, and prostaglandins in the transition of the pulmonary circulation. Clin Perinatol 22:387-403

12. Dukarm RC, Morin FC 3rd, Russell JA, Steinhorn RH 1998 Pulmonary and systemic effects of the phosphodiesterase inhibitor dipyridamole in newborn lambs with persistent pulmonary hypertension. Pediatr Res 44:831-837

13. Morin FC 3rd 1989 Ligating the ductus arteriosus before birth causes persistent pulmonary hypertension in the newborn lamb. Pediatr Res 25:245-250.

14. Wild LM, Nickerson PA, Morin FC 3rd 1989 Ligating the ductus arteriosus before birth remodels the pulmonary vasculature of the lamb. Pediatr Res 25:251-257.

15. Shaul PW, Yuhanna IS, German Z, Chen Z, Steinhorn RH, Morin FC 3rd 1997 Pulmonary endothelial NO synthase gene expression is decreased in fetal lambs with pulmonary hypertension. Am J Physiol 272:L1005-L1012.

16. Steinhorn RH, Albert G, Swartz DD, Russell JA, Levine CR, Davis JM 2001 Recombinant human superoxide dismutase enhances the effect of inhaled nitric oxide in persistent pulmonary hypertension. Am J Respir Crit Care Med 164:834-839

17. Haraldsson A, Kieler-Jensen N, Nathorst-Westfelt U, Bergh CH, Ricksten SE 1998 Comparison of inhaled nitric oxide and inhaled aerosolized prostacyclin in the evaluation of heart transplant candidates with elevated pulmonary vascular resistance. Chest 114:780-786

18. Zobel G, Dacar D, Rodl S, Friehs I 1995 Inhaled nitric oxide versus inhaled prostacyclin and intravenous versus inhaled prostacyclin in acute respiratory failure with pulmonary hypertension in piglets. Pediatr Res 38:198-204

19. Walmrath D, Schneider T, Pilch J, Grimminger F, Seeger W 1993 Aerosolised prostacyclin in adult respiratory distress syndrome. Lancet 342:961-962

20. Pappert D, Busch T, Gerlach H, Lewandowski K, Radermacher P, Rossaint R 1995 Aerosolized prostacyclin versus inhaled nitric oxide in children with severe acute respiratory distress syndrome. Anesthesiology 82:1507-1511

21. Walmrath D, Schneider T, Pilch J, Schermuly R, Grimminger F, Seeger W 1995 Effects of aerosolized prostacyclin in severe pneumonia. Impact of fibrosis. Am J Respir Crit Care Med 151:724-730

22. Hache M, Denault A, Belisle S, Robitaille D, Couture P, Sheridan P, Pellerin M, Babin D, Noel N, Guertin MC, Martineau R, Dupuis J 2003 Inhaled epoprostenol (prostacyclin) and pulmonary hypertension before cardiac surgery. J Thorac Cardiovasc Surg 125:642-649

23. De Jaegere AP, van den Anker JN 1998 Endotracheal instillation of prostacyclin in preterm infants with persistent pulmonary hypertension. Eur Respir J 12:932-934

24. Kelly LK, Porta NF, Goodman DM, Carroll CL, Steinhorn RH 2002 Inhaled prostacyclin for term infants with persistent pulmonary hypertension refractory to inhaled nitric oxide. J Pediatr 141:830-832

25. Feneck RO 1992 Intravenous milrinone following cardiac surgery: I. Effects of bolus infusion followed by variable dose maintenance infusion. The European Milrinone Multicentre Trial Group. J Cardiothorac Vasc Anesth 6:554-562

26. Kato R, Sato J, Nishino T 1998 Milrinone decreases both pulmonary arterial and venous resistances in the hypoxic dog. Br J Anaesth 81:920-924

27. Givertz MM, Hare JM, Loh E, Gauthier DF, Colucci WS 1996 Effect of bolus milrinone on hemodynamic variables and pulmonary vascular resistance in patients with severe left ventricular dysfunction: a rapid test for reversibility of pulmonary hypertension. J Am Coll Cardiol 28:1775-1780

28. Haraldsson A, Kieler-Jensen N, Ricksten SE 2001 The additive pulmonary vasodilatory effects of inhaled prostacyclin and inhaled milrinone in postcardiac surgical patients with pulmonary hypertension. Anesth Analg 93:1439-1445

29. Chang AC, Atz AM, Wernovsky G, Burke RP, Wessel DL 1995 Milrinone: systemic and pulmonary hemodynamic effects in neonates after cardiac surgery. Crit Care Med 23:1907-1914

30. Deb B, Bradford K, Pearl RG 2000 Additive effects of inhaled nitric oxide and intravenous milrinone in experimental pulmonary hypertension. Crit Care Med 28:795-799

31. Schermuly RT, Ghofrani HA, Enke B, Weissmann N, Grimminger F, Seeger W, Schudt C, Walmrath D 1999 Low-dose systemic phosphodiesterase inhibitors amplify the pulmonary vasodilatory response to inhaled prostacyclin in experimental pulmonary hypertension. Am J Respir Crit Care Med 160:1500-1506

32. Schermuly RT, Krupnik E, Tenor H, Schudt C, Weissmann N, Rose F, Grimminger F, Seeger W, Walmrath D, Ghofrani HA 2001 Coaerosolization of phosphodiesterase inhibitors markedly enhances the pulmonary vasodilatory response to inhaled iloprost in experimental pulmonary hypertension. Maintenance of lung selectivity. Am J Respir Crit Care Med 164:1694-1700

33. Schermuly RT, Roehl A, Weissmann N, Ghofrani HA, Schudt C, Tenor H, Grimminger F, Seeger W, Walmrath D 2000 Subthreshold doses of specific phosphodiesterase type 3 and 4 inhibitors enhance the pulmonary vasodilatory response to nebulized prostacyclin with improvement in gas exchange. J Pharmacol Exp Ther 292:512-520 